\title{
Classification of cell death: recommendations of the Nomenclature Committee on Cell Death 2009
}

\author{
G Kroemer ${ }^{*, 1,2,3}$, L Galluzzi ${ }^{1,2,3}$, P Vandenabeele ${ }^{4,5}$, J Abrams ${ }^{6}$, ES Alnemri ${ }^{7}$, EH Baehrecke ${ }^{8}$, MV Blagosklonny ${ }^{9}$, WS El-Deiry $^{10}$, \\ P Golstein ${ }^{11,12,13}$, DR Green ${ }^{14}$, M Hengartner ${ }^{15}$, RA Knight ${ }^{16}$, S Kumar ${ }^{17}$, SA Lipton ${ }^{18,19,20}$, W Malorni ${ }^{21}$, G Nuñez ${ }^{22}$, ME Peter ${ }^{23}$, \\ J Tschopp ${ }^{24}$, J Yuan ${ }^{25}$, M Piacentini ${ }^{26,27}$, B Zhivotovsky ${ }^{28}$ and G Melino $0^{29,30}$
}

Different types of cell death are often defined by morphological criteria, without a clear reference to precise biochemical mechanisms. The Nomenclature Committee on Cell Death (NCCD) proposes unified criteria for the definition of cell death and of its different morphologies, while formulating several caveats against the misuse of words and concepts that slow down progress in the area of cell death research. Authors, reviewers and editors of scientific periodicals are invited to abandon expressions like 'percentage apoptosis' and to replace them with more accurate descriptions of the biochemical and cellular parameters that are actually measured. Moreover, at the present stage, it should be accepted that caspase-independent mechanisms can cooperate with (or substitute for) caspases in the execution of lethal signaling pathways and that 'autophagic cell death' is a type of cell death occurring together with (but not necessarily by) autophagic vacuolization. This study details the 2009 recommendations of the NCCD on the use of cell death-related terminology including 'entosis', 'mitotic catastrophe', 'necrosis', 'necroptosis' and 'pyroptosis'.

Cell Death and Differentiation (2009) 16, 3-11; doi:10.1038/cdd.2008.150; published online 10 October 2008

Cell death can be classified according to its morphological appearance (which may be apoptotic, necrotic, autophagic or associated with mitosis), enzymological criteria (with and without the involvement of nucleases or of distinct classes of proteases, such as caspases, calpains, cathepsins and transglutaminases), functional aspects (programmed or accidental, physiological or pathological) or immunological characteristics (immunogenic or non-immunogenic). ${ }^{1}$

The Nomenclature Committee on Cell Death (NCCD) has formulated a first round of recommendations in 2005, in
Cell Death and Differentiation. ${ }^{2}$ Since then, the field of cell death research has continued its expansion, significant progress has been made and new putative cell death modalities have been described. The NCCD provides a forum in which names describing distinct modalities of cell death are critically evaluated and recommendations on their definition and use are formulated, hoping that a non-rigid, yet uniform, nomenclature will facilitate the communication among scientists and ultimately accelerate the pace of discovery. This study contains the updated NCCD guidelines.

\footnotetext{
${ }^{1}$ INSERM, U848, Villejuif F-94805, France; ${ }^{2}$ Institut Gustave Roussy, Villejuif F-94805, France; ${ }^{3}$ Université Paris Sud-XI, Villejuif F-94805, France; ${ }^{4}$ Department for Molecular Biology, Gent University, Gent B-9052, Belgium; ${ }^{5}$ Department for Molecular Biomedical Research, VIB, Gent B-9052, Belgium; ${ }^{6}$ Department of Cell Biology, UT Southwestern Medical Center, Dallas, TX 75390, USA; ${ }^{7}$ Department of Biochemistry and Molecular Biology, Center for Apoptosis Research, Kimmel Cancer Institute, Thomas Jefferson University, Philadelphia, PA 19107, USA; ${ }^{8}$ Department of Cancer Biology, University of Massachusetts Medical School, Worcester, MA 01605, USA; ${ }^{9}$ Cancer Center, Ordway Research Institute, Albany, NY 12208, USA; ${ }^{10} \mathrm{Hematology-Oncology} \mathrm{Division,} \mathrm{University} \mathrm{of} \mathrm{Pennsylvania} \mathrm{School} \mathrm{of} \mathrm{Medicine,}$ Philadelphia, PA 19104, USA; ${ }^{11}$ Centre d'Immunologie de Marseille-Luminy, Marseille F-13288, France; ${ }^{2}$ CNRS, U631, Marseille F-13288, France; ${ }^{13}$ INSERM, UMR612, Marseille F-13288, France; ${ }^{14}$ Department of Immunology, St Jude Children's Research Hospital, Memphis, TN 38105, USA; ${ }^{15}$ Institute of Molecular Biology, University of Zurich, Zurich CH-8057, Switzerland; ${ }^{16}$ Institute of Child Health, University College London, London WC1N 3JH, UK; ${ }^{17}$ Hanson Institute, IMVS, Adelaide, SA 5000, Australia; ${ }^{18}$ Burnham Institute for Medical Research, San Diego, CA 92037, USA; ${ }^{19}$ The Salk Institute, San Diego, CA 92186, USA; ${ }^{20}$ University of CaliforniaSan Diego, La Jolla, CA 92093, USA; ${ }^{21}$ Department of Therapeutic Research and Medicines Evaluation, Section of Cell Aging and Degeneration, Istituto Superiore di Sanità, Rome I-00161, Italy; ${ }^{22}$ University of Michigan Medical School, Ann Arbor, MI 48109, USA; ${ }^{23}$ Ben May Department for Cancer Research, University of Chicago, Chicago, IL 60637, USA; ${ }^{24}$ Department of Biochemistry, University of Lausanne, Epalinges CH-1066, Switzerland; ${ }^{25}$ Department of Cell Biology, Harvard Medical School, Boston, MA 02115, USA; ${ }^{26}$ Laboratory of Cell Biology, National Institute for Infectious Diseases IRCCS 'L Spallanzani', Rome I-00149, Italy; ${ }^{27}$ Department of Biology, University of Rome 'Tor Vergata', Rome I-00133, Italy; ${ }^{28}$ Division of Toxicology, Institute of Environmental Medicine, Karolinska Institute, Stockholm SE-17111, Sweden; ${ }^{29}$ Department of Experimental Medicine and Biochemical Sciences, University of Rome 'Tor Vergata', Rome I-00133, Italy and ${ }^{30}$ Toxicology Unit, Medical Research Council, Leicester University, Leicester LE1 9HN, UK

${ }^{*}$ Corresponding author: G Kroemer, INSERM U848, Institut Gustave Roussy, Pavillon de Recherche 1, 39 rue Camille Desmoulins, Villejuif F-94805, France.

Tel: + 331421160 46; Fax: + 331421160 47; E-mail: kroemer@igr.fr

Keywords: apoptosis; autophagy; cornification; excitotoxicity; necrosis; Wallerian degeneration

Abbreviations: $\mathrm{Ca}^{2+}$, calcium; $\Delta \Psi_{\mathrm{m}}$, mitochondrial transmembrane potential; IL, interleukin; MMP, mitochondrial membrane permeabilization; NCCD, Nomenclature Committee on Cell Death; PCD, programmed cell death; PI, propidium iodide; Z-VAD-fmk, N-benzyloxycarbonyl-Val-Ala-Asp-fluoromethylketone

Received 03.7.08; revised 29.8.08; accepted 11.9.08; Edited by V De Laurenzi; published online 10.10.08
} 
Recommendation to Authors, Reviewers and Editors of Scientific Journals

Authors still make frequent use of expressions like 'percentage apoptosis' without mentioning the method actually employed to assess ongoing cell death. In a totally inappropriate fashion, these terms are also employed to describe the results of cell-free assays based on purified cellular components. Such a vocabulary is confusing and imprecise and should definitively be abandoned. From 2009, Cell Death and Differentiation will actively enforce a policy in which terms like 'percent apoptosis', 'percent necrosis', 'percent cell death' and 'percent cell survival' must be replaced with more descriptive expressions including 'percent cells with condensed chromatin', 'percent cells with DNA fragmentation', 'percent cells with a low mitochondrial transmembrane potential $\left(\Delta \Psi_{\mathrm{m}}\right)$ ', as well as 'percent propidium iodide $(\mathrm{PI})$ positive', 'percent cleaved caspase-3 positive', 'percent terminal deoxynucleotidyl transferase-mediated dUTP nick end labeling (TUNEL) positive' and 'percent clone forming' cells. Similarly, the term 'percent autophagic cells' should be avoided and replaced with a language that precisely describes what has been measured (such as 'number of GFP-LC3 puncta/cell' or 'percent vacuolated cells'). This applies to the description of experimental results, be it in the text or in the abstract, as well as to the labeling of figures and figure legends. Moreover, NCCD encourages researchers to quantify cell death and/or other catabolic events (such as autophagy) with more than one assay, whenever possible, thereby reducing the probability of artifacts. The NCCD urges all life science journals and, more specifically, all journals in the areas of cell biology, cancer research and pharmacology to pursue a similar policy.

\section{When is a Cell 'Dead'?}

Dying cells are engaged in a process that is reversible until a first irreversible phase or 'point-of-no-return' is trespassed (Table 1). It has been proposed that this step could be represented by massive caspase activation, ${ }^{6}$ loss of $\Delta \Psi_{\mathrm{m}},{ }^{7}$ complete permeabilization of the mitochondrial outer membrane $^{8}$ or exposure of phosphatidylserine (PS) residues that emit 'eat me' signals for normal neighboring cells. However, there are dozens of examples in which caspases are activated in the context of non-lethal processes and differentiation pathways. ${ }^{9,10}$ The $\Delta \Psi_{\mathrm{m}}$ can be dissipated by protonophores without progression to immediate cell death. ${ }^{11} \mathrm{PS}$ exposure can be reversible, for instance in neutrophilic granulocytes. ${ }^{12}$

Table 1 Cell death methodology

\begin{tabular}{|c|c|c|}
\hline Definition & Notes & Methods of detection ${ }^{3-5}$ \\
\hline \multicolumn{3}{|c|}{ Molecular or morphological criteria to define dead cells } \\
\hline $\begin{array}{l}\text { Loss of plasma } \\
\text { membrane integrity }\end{array}$ & $\begin{array}{l}\text { Plasma membrane has broken down, resulting in the } \\
\text { loss of cell's identity }\end{array}$ & $\begin{array}{l}\text { (IF) Microscopy and/or FACS to assess the exclusion of } \\
\text { vital dyes, in vitro }\end{array}$ \\
\hline Cell fragmentation & $\begin{array}{l}\text { The cell (including its nucleus) has undergone complete } \\
\text { fragmentation into discrete bodies (usually referred to } \\
\text { as apoptotic bodies) }\end{array}$ & 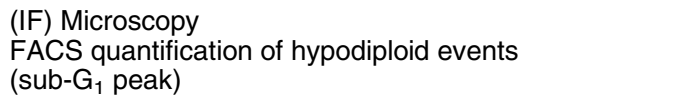 \\
\hline $\begin{array}{l}\text { Engulfment by adjacent } \\
\text { cells }\end{array}$ & $\begin{array}{l}\text { The corpse or its fragments have been phagocytosed } \\
\text { by neighboring cells }\end{array}$ & $\begin{array}{l}\text { (IF) Microscopy } \\
\text { FACS colocalization studies }\end{array}$ \\
\hline \multicolumn{3}{|c|}{ Proposed points-of-no return to define dying cells } \\
\hline $\begin{array}{l}\text { Massive activation of } \\
\text { caspases }\end{array}$ & $\begin{array}{l}\text { Caspases execute the classic apoptotic program, yet in } \\
\text { several instances, caspase-independent death occurs. } \\
\text { Moreover, caspases are involved in non-lethal } \\
\text { processes including differentiation and activation of } \\
\text { cells }\end{array}$ & $\begin{array}{l}\text { Immunoblotting } \\
\text { FACS quantification by means of fluorogenic substrates } \\
\text { or specific antibodies }\end{array}$ \\
\hline$\Delta \Psi_{\mathrm{m}}$ dissipation & $\begin{array}{l}\text { Protracted } \Delta \Psi_{\mathrm{m}} \text { loss usually precedes MMP and cell } \\
\text { death; however, transient dissipation is not always a } \\
\text { lethal event }\end{array}$ & $\begin{array}{l}\text { FACS quantification with } \Delta \Psi_{\mathrm{m}} \text {-sensitive probes } \\
\text { Calcein-cobalt technique }\end{array}$ \\
\hline MMP & $\begin{array}{l}\text { Complete MMP results in the liberation of lethal } \\
\text { catabolic enzymes or activators of such enzymes. } \\
\text { Nonetheless, partial permeabilization may not } \\
\text { necessarily lead to cell death }\end{array}$ & $\begin{array}{l}\text { IF colocalization studies } \\
\text { Immunoblotting after subcellular fractionation }\end{array}$ \\
\hline PS exposure & $\begin{array}{l}\text { PS exposure on the outer leaflet of the plasma } \\
\text { membrane often is an early event of apoptosis, but may } \\
\text { be reversible. PS exposure occurs also in T-cell } \\
\text { activation, without cell death }\end{array}$ & FACS quantification of Annexin V binding \\
\hline \multicolumn{3}{|c|}{ Operative definition of cell death, in particular in cancer research } \\
\hline $\begin{array}{l}\text { Loss of clonogenic } \\
\text { survival }\end{array}$ & $\begin{array}{l}\text { This method does not distinguish cell death from } \\
\text { long-lasting or irreversible cell cycle arrest }\end{array}$ & Clonogenic assays \\
\hline
\end{tabular}

Abbreviations: $\Delta \Psi_{\mathrm{m}}$, mitochondrial transmembrane permeabilization; FACS, fluorescence-activated cell sorter; IF, immunofluorescence; MMP, mitochondria membrane permeabilization; PS, phosphatidylserine 
Thus, the concept of a restriction point for cell death, as it was described by Pardee ${ }^{13}$ for the cell cycle, has yet to be specifically defined.

In the absence of a clearly defined biochemical event that can be considered as the point-of-no-return, the NCCD proposes that a cell should be considered dead when any one of the following molecular or morphological criteria is met: (1) the cell has lost the integrity of its plasma membrane, as defined by the incorporation of vital dyes (e.g., PI) in vitro; (2) the cell, including its nucleus, has undergone complete fragmentation into discrete bodies (which are frequently referred to as 'apoptotic bodies'); and/or (3) its corpse (or its fragments) has been engulfed by an adjacent cell in vivo. Thus, bona fide 'dead cells' would be different from 'dying cells' that have not yet concluded their demise (which can occur through a variety of biochemically distinct pathways, see below). In particular, cells that are arrested in the cell cycle (as it occurs during senescence) should be considered as alive, and the expression 'replicative cell death' (which alludes to the loss of clonogenic potential), as it is frequently used by radiobiologists, should be abandoned.

Definition of 'Apoptosis'. The expression 'apoptosis' has been coined by Kerr et al. ${ }^{14}$ to describe a specific morphological aspect of cell death (Table 2). Apoptosis is accompanied by rounding-up of the cell, retraction of pseudopodes, reduction of cellular volume (pyknosis), chromatin condensation, nuclear fragmentation (karyorrhexis), classically little or no ultrastructural modifications of cytoplasmic organelles, plasma membrane blebbing (but maintenance of its integrity until the final stages of the process) and engulfment by resident phagocytes (in vivo). Hence, the term 'apoptosis' should be applied exclusively to cell death events that occur while manifesting several among these morphological features. It is worth noting that it is not correct to assume that 'programmed cell death' (PCD) and 'apoptosis' are synonyms because cell death, as it occurs during physiological development, can manifest non-apoptotic features. ${ }^{19-21}$

Specific biochemical analyses (such as DNA ladders) should not be employed as an exclusive means to define apoptosis, because this type of cell death can occur without oligonucleosomal DNA fragmentation. Similarly, the presence of proteolytically active caspases or of cleavage products of their substrates is not sufficient to define apoptosis. Frequently, the active suppression (by pharmacological and/or genetic means) of DNA fragmentation and/or caspase activation demonstrates that these changes are not required for the execution of the cell death program, although caspase activation may be necessary for the acquisition of the apoptotic morphology. ${ }^{22-24}$ Moreover, the presence of active caspases and/or of specific products of their enzymatic activity can be linked to non-lethal biological processes. ${ }^{9,10}$ The measurement of DNA fragmentation and/or of caspase activation, however, may be helpful in diagnosing apoptosis. Thus, it may be reasonable to use caspase activation not only to diagnose but also to better define (together with other features) the type of cell death.

It should be noted that the expression 'apoptosis' hides a major degree of biochemical and functional heterogeneity.
There are several distinct subtypes of apoptosis that, although morphologically similar, can be triggered through different biochemical routes (for instance through the 'intrinsic' or the 'extrinsic' pathway, with or without the contribution of mitochondria, etc...). ${ }^{25,26}$ Moreover, the apparent uniformity of apoptotic cell death may conceal heterogeneous functional aspects, for instance concerning the perception of apoptosis by the immune system. ${ }^{27}$ Thus, although apoptosis mostly occurs in a non-immunogenic fashion, some lethal stimuli can lead to the exposure or secretion of proteins that elicit the engulfment of apoptotic material by dendritic cells, followed by efficient antigen presentation and stimulation of a specific immune response. ${ }^{28}$

Cell death is frequently considered to be 'caspasedependent' when it is suppressed by broad-spectrum caspase inhibitors such as $\mathrm{N}$-benzyloxycarbonyl-Val-Ala-Asp-fluoromethylketone (Z-VAD-fmk). As a word of caution, however, it should be noted that Z-VAD-fmk does not act on all caspases with an equal efficiency, and it also inhibits calpains and cathepsins, especially at high concentrations $(>10 \mu \mathrm{M})$. Moreover, Z-VAD-fmk has been associated with several off-target effects that would result from the binding to cysteines on proteins other than cysteine proteases. ${ }^{29}$ As an example, Z-VAD-fmk has been shown to interfere with the interaction between the adenine nucleotide translocase and cyclophylin $D,{ }^{30}$ thereby favoring necrotic cell death. ${ }^{31}$ For these reasons, the term 'Z-VAD-fmk-inhibitable' should be preferred to 'caspase-dependent'. A second difficulty arises from the fact that caspase inhibition often prevents the appearance of some morphological signs of apoptosis (such as chromatin condensation and DNA fragmentation), yet only retards cell death. ${ }^{32}$ In many instances, caspase inhibition simply induces a shift from an apoptotic to a mixed cell death morphology, or even to full-blown pictures of necrosis or autophagic cell death, which, however, may manifest some delay. ${ }^{33}$ Thus, 'caspase-independent cell death' ${ }^{32}$ can occur despite the efficient inhibition of caspases and can exhibit some of the morphological signs of apoptosis (such as a partial chromatin condensation), ${ }^{34}$ autophagy or necrosis.

\section{Considerations on 'Autophagy' and 'Autophagic Cell Death'}

Macroautophagy is characterized by the sequestration of cytoplasmic material within autophagosomes for bulk degradation by lysosomes. Autophagosomes, by definition, are two-membraned and contain degenerating cytoplasmic organelles or cytosol, ${ }^{35,36}$ which allows them to be distinguished by transmission electron microscopy from other types of vesicles such as endosomes, lysosomes or apoptotic blebs. ${ }^{3}$ The fusion between autophagosomes and lysosomes generates autolysosomes, in which both the autophagosome inner membrane and its luminal content are degraded by acidic lysosomal hydrolases. This catabolic process marks the completion of the autophagic pathway. When the fusion of autophagosomes with lysosomes is blocked, the former accumulate in spite of autophagy inhibition. ${ }^{36,37}$ Hence, a massive increase in the number of autophagosomes is by no means a demonstration that the autophagic pathway is induced, and functional tests are required to investigate 
Table 2 Distinct modalities of cell death

\begin{tabular}{|c|c|c|}
\hline Cell death mode & Morphological features & Notes \\
\hline Apoptosis & $\begin{array}{l}\text { Rounding-up of the cell } \\
\text { Retraction of pseudopodes } \\
\text { Reduction of cellular and nuclear volume (pyknosis) } \\
\text { Nuclear fragmentation (karyorrhexis) } \\
\text { Minor modification of cytoplasmic organelles } \\
\text { Plasma membrane blebbing } \\
\text { Engulfment by resident phagocytes, in vivo }\end{array}$ & $\begin{array}{l}\text { 'Apoptosis' is the original term introduced by Kerr et al. }{ }^{14} \text { to } \\
\text { define a type of cell death with specific morphological } \\
\text { features. Apoptosis is NOT a synonym of programmed } \\
\text { cell death or caspase activation. }\end{array}$ \\
\hline Autophagy & $\begin{array}{l}\text { Lack of chromatin condensation } \\
\text { Massive vacuolization of the cytoplasm } \\
\text { Accumulation of (double-membraned) autophagic vacuoles } \\
\text { Little or no uptake by phagocytic cells, in vivo }\end{array}$ & $\begin{array}{l}\text { 'Autophagic cell death' defines cell death occurring with } \\
\text { autophagy, though it may misleadingly suggest a form of } \\
\text { death occurring by autophagy as this process often } \\
\text { promotes cell survival. } 15,16\end{array}$ \\
\hline Cornification & $\begin{array}{l}\text { Elimination of cytosolic organelles } \\
\text { Modifications of plasma membrane } \\
\text { Accumulation of lipids in F and L granules } \\
\text { Extrusion of lipids in the extracellular space } \\
\text { Desquamation (loss of corneocytes) by protease activation }\end{array}$ & $\begin{array}{l}\text { 'Cornified envelope' formation or 'keratinization' is specific of } \\
\text { the skin to create a barrier function. Although apoptosis can } \\
\text { be induced by injury in the basal epidermal layer (e.g., UV } \\
\text { irradiation), cornification is exclusive of the upper layers } \\
\text { (granular layer and stratum corneum). }{ }^{17,18}\end{array}$ \\
\hline Necrosis & $\begin{array}{l}\text { Cytoplasmic swelling (oncosis) } \\
\text { Rupture of plasma membrane } \\
\text { Swelling of cytoplasmic organelles } \\
\text { Moderate chromatin condensation }\end{array}$ & $\begin{array}{l}\text { 'Necrosis' identifies, in a negative fashion, cell death lacking } \\
\text { the features of apoptosis or autophagy. }{ }^{4} \text { Note that necrosis } \\
\text { can occur in a regulated fashion, involving a precise } \\
\text { sequence of signals. }\end{array}$ \\
\hline
\end{tabular}

autophagy. A very comprehensive description of the assays for monitoring autophagy in higher eukaryotes and a set of guidelines for their interpretation has been recently provided by Klionsky et al. ${ }^{38}$ One technique commonly employed to detect autophagy relies on the redistribution of GFP-LC3 fusion proteins into vesicular structures (which can be autophagosomes or autolysosomes). ${ }^{3,39}$ However, the exclusive use of GFP-LC3 as a marker of autophagy is not sufficient to diagnose an enhanced autophagic catabolism. ${ }^{38}$

'Autophagic cell death' is morphologically defined (especially by transmission electron microscopy) as a type of cell death that occurs in the absence of chromatin condensation but accompanied by massive autophagic vacuolization of the cytoplasm. In contrast to apoptotic cells (whose clearance is ensured by engulfment and lysosomal degradation), cells that die with an autophagic morphology have little or no association with phagocytes. ${ }^{40,41}$ Although the expression 'autophagic cell death' is a linguistic invitation to believe that cell death is executed by autophagy, the term simply describes cell death with autophagy. ${ }^{15,16,42}$ Thus far, involuting Drosophila melanogaster salivary glands provide the only in vivo evidence that the knockdown/knockout of genes required for autophagy truly reduces cell death. ${ }^{43}$ This may be due to the limited number of studies that have investigated autophagic cell death in vivo, although there are no doubts that autophagy promotes cell survival, in multiple physiological and experimental settings. ${ }^{44}$ Significantly, some reports indicate that cells presenting features of 'autophagic cell death' can still recover upon withdrawal of the death-inducing stimulus. ${ }^{45}$ In most cases described to date in which autophagy is suppressed by genetic knockout/knockdown of essential autophagy (atg) genes, cell death is not inhibited but rather occurs at an accelerated pace,$^{15}$ pointing to the prominent role of autophagy as a pro-survival pathway. This said, it should be noted that most of these studies have been performed on immortalized cell lines in vitro and that autophagic cell death rarely affects individual cells in vivo. ${ }^{19,41}$ Nevertheless, in specific cases, autophagy may participate in the destruction of cells, as a result of a protracted atrophy of the cytoplasm, beyond a not yet clearly defined point-of-noreturn. ${ }^{43,46}$ Thus, direct induction of autophagy by overexpression of the Atg1 kinase is sufficient to kill fat and salivary gland cells in Drosophila. Interestingly, although Atg1-driven autophagic cell death entails caspase-dependent mechanisms in fat cells, ${ }^{46}$ the same does not hold true in salivary gland cells (which cannot be rescued from Atg1induced death by p35 expression). ${ }^{43}$

\section{Definition of 'Necrosis'}

'Necrotic cell death' or 'necrosis' is morphologically characterized by a gain in cell volume (oncosis), swelling of organelles, plasma membrane rupture and subsequent loss of intracellular contents. For a long time, necrosis has been considered merely as an accidental uncontrolled form of cell death, but evidence is accumulating that the execution of necrotic cell death may be finely regulated by a set of signal transduction pathways and catabolic mechanisms. ${ }^{4,47}$ For instance, death domain receptors (e.g., TNFR1, Fas/CD95 and TRAIL-R) and Toll-like receptors (e.g., TLR3 and TLR4) have been shown to elicit necrosis, in particular in the presence of caspase inhibitors. TNFR1-, Fas/CD95-, TRAILR- and TLR3-mediated cell death seemingly depends on the kinase RIP1, ${ }^{48}$ as this has been demonstrated by its knockout/knockdown and chemical inhibition with necrostatin1. ${ }^{49-51}$ Although there is no generalized consensus on the use of this expression, some authors have proposed the term 'necroptosis' to indicate regulated (as opposed to accidental) necrosis. At a biochemical level, necroptosis may be defined 
as a type of cell death that can be avoided by inhibiting RIP1 (either through genetic or pharmacological methods), ${ }^{49,50}$ which may represent a convenient means to discriminate between programmed and fortuitous forms of necrosis.

Several mediators, organelles and cellular processes have been implicated in necrotic cell death, but it is still unclear how they interrelate with each other. The causative elements of necrosis are unclear, as well as its bystander effects. These phenomena include mitochondrial alterations (e.g., uncoupling, production of reactive oxygen species, i.e., ROS, nitroxidative stress by nitric oxide or similar compounds $^{52}$ and mitochondrial membrane permeabilization, i.e., MMP, often controlled by cyclophilin D), lysosomal changes (ROS production by Fenton reactions, lysosomal membrane permeabilization), nuclear changes (hyperactivation of PARP-1 and concomitant hydrolysis of $\mathrm{NAD}^{+}$), lipid degradation (following the activation of phospholipases, lipoxygenases and sphingomyelinases), increases in the cytosolic concentration of calcium $\left(\mathrm{Ca}^{2+}\right)$ that result in mitochondrial overload and activation of non-caspase proteases (e.g., calpains and cathepsins). ${ }^{4,53}$ In several (but not all) instances of necrotic cell death, a crucial role for the serine/threonine kinase RIP1 has been demonstrated. ${ }^{54}$ Thus far, however, there is no consensus on the biochemical changes that may be used to unequivocally identify necrosis. In the absence of a common biochemical denominator, necrotic cell death is still largely identified in negative terms by the absence of apoptotic or autophagic markers, in particular when the cells undergo early plasma membrane permeabilization (as compared with its delayed occurrence, which is associated with late-stage apoptosis). For these reasons, caution should be used in classifying particular cell death routines as necrotic.

\section{Definition of 'Cornification'}

Cornification is a very specific form of PCD that occurs in the epidermis, morphologically and biochemically distinct from apoptosis. It leads to the formation of corneocytes, that is dead keratinocytes containing an amalgam of specific proteins (e.g., keratin, loricrin, SPR and involucrin) and lipids (e.g., fatty acids and ceramides), which are necessary for the function of the cornified skin layer (mechanical resistance, elasticity, water repellence and structural stability). Cornification is less often referred to as 'keratinization' or 'cornified envelope formation', ${ }^{17,55}$ and it is generally considered as a terminal differentiation program similar to those leading to other anucleated tissues (such as the lens epithelium and mature red blood cells). ${ }^{56,57}$ This is mainly due to the fact that these processes display the (often limited) activation of the molecular machinery for cell death, in particular of caspases. $^{9,10,57,58}$ In contrast with corneocytes, however, both mature red blood and lens epithelial cells retain the ability to undergo stress-induced death, ${ }^{59,60}$ and hence only cornification should be regarded as a bona fide cell death program.

At the molecular level, cornification follows a specific mechanism of epithelial differentiation during which cells express all enzymes and substrates required for building up the epidermal barrier that allows for isolating the body from the external environment. This is obtained by the crosslinking enzymes (e.g., transglutaminase types 1, 3 and 5) acting on several substrates (e.g., loricrin, SPR, involucrin and SP100) ${ }^{18}$ as well as through the synthesis of specific lipids that are released into the extracellular space (where they are covalently attached to cornified envelope proteins), and proteases, which are required for impermeability and desquamation, respectively.

\section{Tentative Definitions of Atypical Cell Death Modalities}

'Mitotic catastrophe'. Mitotic catastrophe is a cell death mode occurring either during or shortly after a dysregulated/ failed mitosis and can be accompanied by morphological alterations including micronucleation (which often results from chromosomes and/or chromosome fragments that have not been distributed evenly between daughter nuclei) and multinucleation (the presence of two or more nuclei with similar or heterogeneous sizes, deriving from a deficient separation during cytokinesis). However, there is no broad consensus on the use of this term, ${ }^{61-63}$ and mitotic catastrophe can lead either to an apoptotic morphology or to necrosis. ${ }^{64}$ As a result, the NCDD recommends the use of expressions such as 'cell death preceded by multinucleation' or 'cell death occurring during metaphase', which are more precise and more informative.

'Anoikis'. Apoptosis induced by the loss of the attachment to the substrate or to other cells is called anoikis. ${ }^{65}$ Besides its specific form of induction, the molecular mechanisms of anoikis-associated cell death match those activated during classical apoptosis. ${ }^{66}$ The NCCD acknowledges the use of this term for historical reasons, as it is already quite diffuse in the literature. However, it will be necessary to determine whether under certain circumstances other modalities of cell death occur in vivo following detachment, that is, whether there are forms of anoikis refractory to caspase inhibitors and/or others that manifest necrotic features.

'Excitotoxicity'. This is a form of cell death occurring in neurons challenged with excitatory amino acids, such as glutamate, that leads to the opening of the $N$-methyl-Daspartate $\mathrm{Ca}^{2+}$-permeable channel, followed by cytosolic $\mathrm{Ca}^{2+}$ overload and activation of lethal signaling pathways. ${ }^{67}$ Excitotoxicity seemingly overlaps with other types of death such as apoptosis and necrosis (depending on the intensity of the initiating stimulus), and involves MMP as a critical event. For these reasons, and for the presence of common regulators such as nitric oxide itself, ${ }^{68}$ excitotoxicity cannot be considered as a separate cell death modality.

'Wallerian degeneration'. Additional less-characterized forms of cellular catabolism take place in the nervous system, such as Wallerian degeneration, in which part of a neuron or axon degenerates without affecting the main cell body. ${ }^{69,70}$ This term does not describe a type of cell death sensu stricto, because neurons affected by Wallerian degeneration remain alive. ${ }^{70}$ 
'Paraptosis'. This term was originally introduced to describe a form of PCD morphologically and biochemically distinct from apoptosis. ${ }^{71}$ In multiple cell types, paraptosis was triggered by the expression of the insulin-like growth factor receptor I, and it was associated with extensive cytoplasmic vacuolization and mitochondrial swelling, but without any other morphological hallmark of apoptosis. ${ }^{71}$ The manifestations of paraptosis could not be prevented by caspase inhibitors, nor by the overexpression of antiapoptotic Bcl-2-like proteins, ${ }^{71,72}$ and seemingly resulted from a signaling cascade involving specific members of the mitogen-activated protein kinase family. ${ }^{72}$ At present, it is still unclear whether paraptosis represents a route of cell death that is truly distinct from all others.

'Pyroptosis'. Pyroptosis has first been described in macrophages infected with Salmonella typhimurium. ${ }^{73}$ It involves the apical activation of caspase-1 (but not of caspase-3), a protease that is mostly known as interleukin$1 \beta$ (IL-1 $\beta)$-converting enzyme. Caspase-1 activation induced by $S$. typhimurium (and by other pathogens such as Pseudomonas aeruginosa and Shigella flexneri) occurs through Ipaf, ${ }^{74-76}$ an Apaf-1-related NLR protein. ${ }^{78}$ In contrast, pyroptosis induced by Bacillus anthracis lethal toxin does not require Ipaf and rather involves another NLR protein, that is Nalp1. ${ }^{78}$ In addition, lipopolysaccharidetreated macrophages (either in the presence or in the absence of ATP) undergo pyroptosis mediated by the adaptor protein ASC, which together with caspase-1 forms a supramolecular cytoplasmic complex also known as 'pyroptosome'. ${ }^{79}$ Thus, distinct routes to caspase-1 activation induce pyroptosis. As this form of cell death leads to the release of IL- $1 \beta$ (which is one of the major feverinducing cytokines or pyrogens) and of IL-18, it may play a relevant role in both local and systemic inflammatory reactions. $^{80,81}$ As it stands, macrophages undergoing pyroptosis not only exhibit morphological features that are typical of apoptosis, but also display some traits associated with necrosis. ${ }^{82}$

'Pyronecrosis'. Nalp3 and ASC are involved in the necrotic cell death of macrophages infected by $S$. flexneri at high bacteria/macrophage ratios and associated with the release of HMGB-1, caspase-1 and $\mathrm{IL}-1 \beta$, which is called pyronecrosis. ${ }^{83}$ Pyronecrosis and pyroptosis are distinguished based on the fact that the latter (but not the former) requires caspase-1. It remains to be determined whether RIP1 is implicated in pyronecrosis, as well as whether pyroptosis and pyronecrosis play any role outside of the innate immune system. ${ }^{84,85}$

'Entosis'. Entosis, originally described as a form of 'cellular cannibalism' in lymphoblasts from patients with Huntington's disease ${ }^{86}$ has been reported as a new cell death modality in which one cell engulfs one of its live neighbors, which then dies within the phagosome. ${ }^{87}$ Intriguingly, the most efficient cells in performing entosis are MCF-7 breast cancer cells, ${ }^{87,88}$ which lack both caspase-3 and beclin-1 and hence are (relatively) apoptosis- and autophagyincompetent. This points to the possibility, which remains to be explored, that entosis is a default pathway that is unmasked (and hence can be observed) exclusively when other catabolic reactions are suppressed. Entosis is not inhibited by Bcl-2 or Z-VAD-fmk, and internalized cells appear virtually normal. Later they disappear, presumably through lysosomal degradation. In rare cases, however, internalized cells are able to divide within the engulfing cell or are released. ${ }^{87}$ Hence, it is difficult to know whether the cellin-cell morphology (entosis) truly represents a novel cell death modality. 89

\section{Postface}

As it stands, three distinct routes of cellular catabolism can be defined according to morphological criteria, namely apoptosis (which is a form of cell death), autophagy (which causes the destruction of a part of the cytoplasm, but mostly avoids cell death) and necrosis (which is another form of cell death). Although frequently employed in the past, the use of Roman numerals (i.e., type I, type II and type III cell death, respectively) to indicate these catabolic processes should be abandoned. Moreover, several critiques can be formulated against the clear-cut distinction of different cell types in the triad of apoptosis, autophagic cell death and necrosis.

First, although this vocabulary was originally introduced based on observations of developing animals, ${ }^{41,90}$ it has rapidly been adopted to describe the results of in vitro studies performed on immortalized cell lines, which reflect very poorly the physiology of cell death in vivo. In tissues, indeed, dying cells are usually engulfed well before signs of advanced apoptosis or necrosis become detectable. Thus, it may be acceptable - if the irreversibility of these phenomena is demonstrated - to assess caspase activation and/or DNA fragmentation to diagnose apoptotic cell death in vivo.

Second, there are numerous examples in which cell death displays mixed features, for instance with signs of both apoptosis and necrosis, a fact that lead to the introduction of terms like 'necroapoptosis' and 'aponecrosis' (whose use is discouraged by the NCCD to avoid further confusion). ${ }^{53}$ Similarly, in the involuting $D$. melanogaster salivary gland, autophagic vacuolization is synchronized with signs of apoptosis, ${ }^{91}$ and results from genetic studies indicate that caspases and autophagy act in an additive manner to ensure cell death in this setting. ${ }^{43}$ Altogether, these data argue against a clear-cut and absolute distinction between different forms of cell death based on morphological criteria.

Third (and most important), it would be a desideratum to replace morphological aspects with biochemical/functional criteria (Table 3 ) to classify cell death modalities. Unfortunately, there is no clear equivalence between morphology and biochemistry, suggesting that the ancient morphological terms are doomed to disappear and to be replaced by truly biochemical definitions. In this context, 'loss-of-function' and 'gain-of function' genetic approaches (e.g., RNA interference, knockout models and plasmid-driven overexpression systems) represent invaluable tools to characterize cell death modes with more precision, but only if such interventions truly reduce/augment the rate of death, instead of changing its morphological appearance (as it is often the case). Present cell death classifications are reminiscent of the categorization 
Table 3 Biochemical aspects of distinct modalities of cellular catabolism

$\begin{array}{lll}\text { Cell death Biochemical features } \quad \text { Methods for detection } & \\ \text { mode } & \end{array}$

mode

Apoptosis Activation of proapoptotic Bcl-2 family IF microscopy localization studies

proteins (e.g., Bax, Bak, Bid) Immunoblotting with conformation-specific antibodies

Activation of caspases

Colorimetric/fluorogenic substrate-based assays in live cells

Colorimetric/fluorogenic substrate-based assays of lysates in microtiter plates

FACS/IF microscopy quantification with antibodies specifically recognizing the active form of caspases

FACS/IF microscopy quantification with antibodies specific for cleaved caspase substrates

FACS/IF microscopy quantification with fluorogenic substrates

Immunoblotting assessment of caspase-activation state

Immunoblotting assessment of the cleavage of caspase products

$\Delta \Psi_{\mathrm{m}}$ dissipation

Calcein-cobalt technique (FACS/IF microscopy)

FACS/IF microscopy quantification with $\Delta \Psi_{\mathrm{m}}$-sensitive probes

Oxygen-consumption studies (polarography)

MMP

Colorimetric techniques to assess the accessibility of exogenous substrates to IM-embedded enzymatic activities

FACS-assisted detection of IMS proteins upon plasma membrane permeabilization

FACS-assisted detection of physical parameters of purified mitochondria

HPLC-assisted quantification of mitochondrial alterations in purified mitochondria

IF microscopy colocalization studies of IMS proteins (e.g., Cyt $c$ ) with sessile mitochondrial

proteins (e.g., VDAC1)

IF (video) microscopy with Cyt $c$-GFP fusion protein

Immunoblotting detection of IMS proteins (e.g., Cyt $c$ ) upon cellular fractionation

Oligonucleosomal DNA fragmentation DNA ladders

FACS quantification of hypodiploid cells (sub- $\mathrm{G}_{1}$ peak)

TUNEL assays

Plasma membrane rupture

Colorimetric/fluorogenic substrate-based assays of culture supernatants in microtiter plates to determine the release of cytosolic enzymatic activities

(e.g., LDH)

FACS quantification with vital dyes

PS exposure

ROS overgeneration

FACS quantification of Annexin $\mathrm{V}$ binding

FACS/IF microscopy quantification with ROS-sensitive probes

ssDNA accumulation

FACS quantification with ssDNA-specific antibodies

Autophagy Beclin-1 dissociation from Bcl-2/ $\mathrm{X}_{\mathrm{L}}$ Dependency on atg gene products LC3-I to LC3-II conversion

p62 $2^{\text {Lck }}$ degradation

Co-immunoprecipitation studies

Genetic studies (e.g., knockout models, RNA interference, plasmid-driven overexpression systems) IF microscopy with GFP-LC3 fusion protein Immunoblotting with LC3-specific antibodies

Immunoblotting with p62-specific antibodies

Cornification Expression of TGs

Expression of TG substrates

Immunoblotting with antibodies specific for TG type 1, 3 and 5 qRT-PCR

Immunoblotting with antibodies specific for TG substrates (e.g., loricrin, SPR, involucrin, keratins)

qRT-PCR

Crosslinking activity

HPLC detection of K-L isodipeptide bonds

Monodansyl-cadaverine incorporation to detect TG activity in tissues

Radiolabeled putrescine incorporation to detect TG activity in cell extracts

Necrosis Activation of calpains

Activation of cathepsins

Colorimetric/fluorogenic substrate-based assays of cell lysates in microtiter plates

Colorimetric/fluorogenic substrate-based assays in live cells

Colorimetric/fluorogenic substrate-based assays of cell lysates in microtiter plates

Luminometric assessments of ATP/ADP ratio

Drop of ATP levels

HMGB-1 release

LMP

Immunoblotting of culture medium with HMGB-1-specific antibodies

FACS quantification with lysomorphotropic probes

Plasma membrane rupture

Colorimetric/fluorogenic substrate-based assays of culture supernatants in microtiter plates to determine the release of cytosolic enzymatic activities (e.g., LDH)

FACS quantification with vital dyes

RIP1 phosphorylation

Immunoblotting with phosphoneoepitope-specific antibodies

RIP1 ubiquitination

Immunoprecipitation with anti-RIP1 antibodies followed by immunoblotting with anti-ubiquitin antibodies

ROS overgeneration

Specific PARP1 cleavage pattern

Immunoblotting with PARP1-specific antibodies

Abbreviations: $\Delta \Psi_{\mathrm{m}}$, mitochondrial transmembrane permeabilization; Cyt $c$, cytochrome $c$; FACS, fluorescence-activated cell sorter; GFP, green fluorescent protein; HPLC, high-pressure liquid chromatography: IF, immunofluorescence; IM, mitochondrial inner membrane; IMS, mitochondrial intermembrane space; LDH, lactate dehydrogenase; LMP, lysosomal membrane permeabilization; MMP, mitochondrial membrane permeabilization; PS, phosphatidylserine; qRT-PCR, real-time quantitative reverse transcription PCR; ROS, reactive oxygen species; RNAi, RNA interference; TG, transglutaminase; TUNEL, terminal deoxynucleotidyl transferase-mediated dUTP nick-end labeling; VDAC1, voltage-dependent anion channel 1 
of tumors that has been elaborated by pathologists over the last one and a half centuries. As old morphological categorizations of tumors are being more and more supported (and will presumably be replaced) by molecular diagnostics (which allows for a more sophisticated stratification of cancer subtypes based on molecular criteria), the current catalog of cell death types is destined to lose its value as compared with biochemical/functional tests. In the end, such efforts of classification are only justified when they have a prognostic and/or predictive impact, allowing the matching of each individual cancer with the appropriate therapy. Similarly, a cell death nomenclature will be considered useful only if it predicts the possibilities to pharmacologically/genetically modulate (induce or inhibit) cell death and/or if it predicts the consequences of cell death in vivo, with regard to inflammation and recognition by the immune system.

Acknowledgements. The NCCD acknowledges the valuable input of all editors of Cell Death and Differentiation as well as that of numerous colleagues who helped shaping the present recommendations in scientific meetings.

1. Melino G. The Sirens' song. Nature 2001; $412: 23$

2. Kroemer G, El-Deiry WS, Golstein P, Peter ME, Vaux D, Vandenabeele P et al Classification of cell death: recommendations of the Nomenclature Committee on Cell Death. Cell Death Differ 2005; 12 (Suppl 2): 1463-1467.

3. Tasdemir E, Galluzzi L, Maiuri MC, Criollo A, Vitale I, Hangen E et al. Methods for assessing autophagy and autophagic cell death. Methods Mol Biol 2008; 445: 29-76.

4. Golstein P, Kroemer G. Cell death by necrosis: towards a molecular definition. Trends Biochem Sci 2007; 32: 37-43.

5. Galluzzi L, Zamzami N, de La Motte Rouge T, Lemaire C, Brenner C, Kroemer G. Methods for the assessment of mitochondrial membrane permeabilization in apoptosis. Apoptosis 2007; 12: 803-813

6. Cohen GM. Caspases: the executioners of apoptosis. Biochem J 1997; 326 (Part 1): 1-16

7. Green D, Kroemer G. The central executioners of apoptosis: caspases or mitochondria? Trends Cell Biol 1998; 8: 267-271.

8. Green DR, Kroemer G. The pathophysiology of mitochondrial cell death. Science 2004 305: $626-629$

9. Garrido C, Kroemer G. Life's smile, death's grin: vital functions of apoptosis-executing proteins. Curr Opin Cell Biol 2004; 16: 639-646.

10. Galluzzi L, Joza N, Tasdemir E, Maiuri MC, Hengartner M, Abrams JM et al. No death without life: vital functions of apoptotic effectors. Cell Death Differ 2008; 15: 1113-1123.

11. de Graaf AO, van den Heuvel LP, Dijkman HB, de Abreu RA, Birkenkamp KU, de Witte T et al. Bcl-2 prevents loss of mitochondria in CCCP-induced apoptosis. Exp Cell Res 2004; 299: 533-540.

12. Yang MY, Chuang $H$, Chen RF, Yang KD. Reversible phosphatidylserine expression on blood granulocytes related to membrane perturbation but not DNA strand breaks. J Leukoc Biol 2002; 71: 231-237.

13. Pardee AB. A restriction point for control of normal animal cell proliferation. Proc Natl Acad Sci USA 1974; 71: 1286-1290.

14. Kerr JF, Wyllie AH, Currie AR. Apoptosis: a basic biological phenomenon with wide-ranging implications in tissue kinetics. Br J Cancer 1972; 26: 239-257.

15. Galluzzi L, Vicencio JM, Kepp O, Tasdemir E, Maiuri MC, Kroemer G. To die or not to die: that is the autophagic question. Curr Mol Med 2008; 8: 78-91.

16. Levine B, Yuan J. Autophagy in cell death: an innocent convict? J Clin Invest 2005; 115 2679-2688

17. Candi E, Schmidt R, Melino G. The cornified envelope: a model of cell death in the skin. Nat Rev Mol Cell Biol 2005; 6: 328-340.

18. Melino G, Candi E, Steinert PM. Assays for transglutaminases in cell death. Methods Enzymol 2000; 322: 433-472.

19. Baehrecke EH. How death shapes life during development. Nat Rev Mol Cell Biol 2002; 3 779-787.

20. Barkla DH, Gibson PR. The fate of epithelial cells in the human large intestine. Pathology 1999; 31: 230-238.

21. Roach HI, Clarke NM. Physiological cell death of chondrocytes in vivo is not confined to apoptosis. New observations on the mammalian growth plate. J Bone Joint Surg Br 2000; 82: 601-613.

22. Kroemer G, Martin SJ. Caspase-independent cell death. Nat Med 2005; 11: 725-730.
23. Kumar S. Caspase function in programmed cell death. Cell Death Differ 2007; 14: $32-43$

24. Lamkanfi M, Festjens N, Declercq W, Vanden Berghe T, Vandenabeele P. Caspases in cell survival, proliferation and differentiation. Cell Death Differ 2007; 14: 44-55.

25. Danial NN, Korsmeyer SJ. Cell death: critical control points. Cell 2004; 116: 205-219.

26. Kroemer G, Galluzzi L, Brenner C. Mitochondrial membrane permeabilization in cell death. Physiol Rev 2007; 87: 99-163.

27. Obeid M, Tesniere A, Ghiringhelli F, Fimia GM, Apetoh L, Perfettini JL et al. Calreticulin exposure dictates the immunogenicity of cancer cell death. Nat Med 2007; 13: 54-61.

28. Zitvogel L, Apetoh L, Ghiringhelli F, Kroemer G. Immunological aspects of cancer chemotherapy. Nat Rev Immunol 2008; 8: 59-73.

29. Vandenabeele P, Vanden Berghe T, Festjens N. Caspase inhibitors promote alternative cell death pathways. Sci STKE 2006; 2006: pe44

30. Temkin V, Huang $Q$, Liu $H$, Osada $H$, Pope RM. Inhibition of ADP/ATP exchange in receptor-interacting protein-mediated necrosis. Mol Cell Biol 2006; 26: 2215-2225.

31. Vercammen D, Beyaert R, Denecker G, Goossens V, Van Loo G, Declercq W et al. Inhibition of caspases increases the sensitivity of L929 cells to necrosis mediated by tumor necrosis factor. J Exp Med 1998; 187: 1477-1485.

32. Chipuk JE, Green DR. Do inducers of apoptosis trigger caspase-independent cell death? Nat Rev Mol Cell Biol 2005; 6: 268-275.

33. Golstein P, Kroemer G. Redundant cell death mechanisms as relics and backups. Cell Death Differ 2005; 12 (Suppl 2): 1490-1496.

34. Susin SA, Daugas E, Ravagnan L, Samejima K, Zamzami N, Loeffler M et al. Two distinct pathways leading to nuclear apoptosis. J Exp Med 2000; 192: 571-580.

35. Levine B, Klionsky DJ. Development by self-digestion: molecular mechanisms and biological functions of autophagy. Dev Cell 2004; 6: 463-477.

36. Levine B, Kroemer G. Autophagy in the pathogenesis of disease. Cell 2008; 132 27-42.

37. Gonzalez-Polo RA, Boya P, Pauleau AL, Jalil A, Larochette N, Souquere S et al. The apoptosis/autophagy paradox: autophagic vacuolization before apoptotic death. J Cell Sci 2005; 118: 3091-3102.

38. Klionsky DJ, Abeliovich $\mathrm{H}$, Agostinis $\mathrm{P}$, Agrawal DK, Aliev G, Askew DS et al. Guidelines for the use and interpretation of assays for monitoring autophagy in higher eukaryotes. Autophagy 2008; 4: 151-175.

39. Mizushima N, Yamamoto A, Matsui M, Yoshimori T, Ohsumi Y. In vivo analysis of autophagy in response to nutrient starvation using transgenic mice expressing a fluorescent autophagosome marker. Mol Biol Cell 2004; 15: 1101-1111.

40. Baehrecke EH. Autophagy: dual roles in life and death? Nat Rev Mol Cell Biol 2005; 6 : 505-510.

41. Clarke PG. Developmental cell death: morphological diversity and multiple mechanisms. Anat Embryol (Berl) 1990; 181: 195-213.

42. Galluzzi L, Maiuri MC, Vitale I, Zischka H, Castedo M, Zitvogel L et al. Cell death modalities: classification and pathophysiological implications. Cell Death Differ 2007; 14: 1237-1243.

43. Berry DL, Baehrecke EH. Growth arrest and autophagy are required for salivary gland cell degradation in Drosophila. Cell 2007; 131: 1137-1148.

44. Neufeld TP, Baehrecke EH. Eating on the fly: function and regulation of autophagy during cell growth, survival and death in Drosophila. Autophagy 2008; 4: 557-562.

45. Boya P, Gonzalez-Polo RA, Casares N, Perfettini JL, Dessen P, Larochette N et al. Inhibition of macroautophagy triggers apoptosis. Mol Cell Biol 2005; 25: 1025-1040.

46. Scott RC, Juhasz G, Neufeld TP. Direct induction of autophagy by Atg1 inhibits cell growth and induces apoptotic cell death. Curr Biol 2007; 17: 1-11.

47. Festjens N, Vanden Berghe T, Vandenabeele P. Necrosis, a well-orchestrated form of cell demise: signalling cascades, important mediators and concomitant immune response. Biochim Biophys Acta 2006; 1757: 1371-1387.

48. Holler N, Zaru R, Micheau O, Thome M, Attinger A, Valitutti S et al. Fas triggers an alternative, caspase-8-independent cell death pathway using the kinase RIP as effector molecule. Nat Immunol 2000; 1: 489-495.

49. Degterev A, Huang Z, Boyce M, Li Y, Jagtap P, Mizushima N et al. Chemical inhibitor of nonapoptotic cell death with therapeutic potential for ischemic brain injury. Nat Chem Biol 2005; 1: 112-119.

50. Degterev A, Hitomi J, Germscheid M, Ch'en IL, Korkina O, Teng X et al. Identification of RIP1 kinase as a specific cellular target of necrostatins. Nat Chem Biol 2008; 4: 313-321.

51. Kalai M, Van Loo G, Vanden Berghe T, Meeus A, Burm W, Saelens X et al. Tipping the balance between necrosis and apoptosis in human and murine cells treated with interferon and dsRNA. Cell Death Differ 2002; 9: 981-994.

52. Nicotera $P$, Bernassola F, Melino G. Nitric oxide (NO), a signaling molecule with a killer soul. Cell Death Differ 1999; 6: 931-933.

53. Nicotera P, Melino G. Regulation of the apoptosis-necrosis switch. Oncogene 2004; 23 2757-2765

54. Festjens N, Vanden Berghe T, Cornelis S, Vandenabeele P. RIP1, a kinase on the crossroads of a cell's decision to live or die. Cell Death Differ 2007; 14: 400-410.

55. Lippens S, Denecker G, Ovaere P, Vandenabeele P, Declercq W. Death penalty for keratinocytes: apoptosis versus cornification. Cell Death Differ 2005; 12 (Suppl 2): 1497-1508.

56. Counis MF, Chaudun E, Arruti C, Oliver L, Sanwal M, Courtois $Y$ et al. Analysis of nuclear degradation during lens cell differentiation. Cell Death Differ 1998; 5: 251-261.

57. Testa U. Apoptotic mechanisms in the control of enthropoiesis. Leukemia 2004; 18: 1176-1199. 
58. Weber GF, Menko AS. The canonical intrinsic mitochondrial death pathway has a nonapoptotic role in signaling lens cell differentiation. J Biol Chem 2005; 280: 22135-22145

59. Yan Q, Liu JP, Li DW. Apoptosis in lens development and pathology. Differentiation 2006; 74: 195-211.

60. Lang KS, Lang PA, Bauer C, Duranton C, Wieder T, Huber SM et al. Mechanisms of suicidal erythrocyte death. Cell Physiol Biochem 2005; 15: 195-202.

61. Roninson IB, Broude EV, Chang BD. If not apoptosis, then what? Treatmentinduced senescence and mitotic catastrophe in tumor cells. Drug Resist Updat 2001; 4: 303-313.

62. Castedo M, Perfettini JL, Roumier T, Andreau K, Medema R, Kroemer G. Cell death by mitotic catastrophe: a molecular definition. Oncogene 2004; 23: 2825-2837.

63. Okada H, Mak TW. Pathways of apoptotic and non-apoptotic death in tumour cells. Nat Rev Cancer 2004; 4: 592-603.

64. Vakifahmetoglu H, Olsson M, Zhivotovsky B. Death through a tragedy: mitotic catastrophe. Cell Death Differ 2008; 15: 1153-1162.

65. Gilmore AP. Anoikis. Cell Death Differ 2005; 12 (Suppl 2): 1473-1477.

66. Grossmann J. Molecular mechanisms of 'detachment-induced apoptosis-Anoikis' Apoptosis 2002; 7: 247-260.

67. Orrenius S, Zhivotovsky B, Nicotera P. Regulation of cell death: the calcium-apoptosis link Nat Rev Mol Cell Biol 2003; 4: 552-565.

68. Melino G, Bernassola F, Knight RA, Corasaniti MT, Nistico G, Finazzi-Agro A S-nitrosylation regulates apoptosis. Nature 1997; 388: 432-433.

69. Luo L, O'Leary DD. Axon retraction and degeneration in development and disease. Annu Rev Neurosci 2005; 28: 127-156.

70. Raff MC, Whitmore AV, Finn JT. Axonal self-destruction and neurodegeneration. Science 2002; 296: 868-871.

71. Sperandio S, de Belle I, Bredesen DE. An alternative, nonapoptotic form of programmed cell death. Proc Natl Acad Sci USA 2000; 97: 14376-14381.

72. Sperandio S, Poksay K, de Belle I, Lafuente MJ, Liu B, Nasir J et al. Paraptosis: mediation by MAP kinases and inhibition by AIP-1/Alix. Cell Death Differ 2004; 11: 1066-1075.

73. Brennan MA, Cookson BT. Salmonella induces macrophage death by caspase-1dependent necrosis. Mol Microbiol 2000; 38: 31-40.

74. Franchi L, Stoolman J, Kanneganti TD, Verma A, Ramphal R, Nunez G. Critical role for Ipaf in Pseudomonas aeruginosa-induced caspase-1 activation. Eur J Immunol 2007; 37: 3030-3039

75. Suzuki T, Franchi L, Toma C, Ashida H, Ogawa M, Yoshikawa Y et al. Differentia regulation of caspase-1 activation, pyroptosis, and autophagy via Ipaf and ASC in Shigellainfected macrophages. PLoS Pathog 2007; 3: e111.
76. Mariathasan S, Newton K, Monack DM, Vucic D, French DM, Lee WP et al. Differential activation of the inflammasome by caspase-1 adaptors ASC and Ipaf. Nature 2004; 430: 213-218.

77. Poyet JL, Srinivasula SM, Tnani M, Razmara M, Fernandes-Alnemri T, Alnemri ES. Identification of Ipaf, a human caspase-1-activating protein related to Apaf-1. J Biol Chem 2001; 276: 28309-28313.

78. Fink SL, Bergsbaken T, Cookson BT. Anthrax lethal toxin and Salmonella elicit the common cell death pathway of caspase-1-dependent pyroptosis via distinct mechanisms. Proc Natl Acad Sci USA 2008; 105: 4312-4317.

79. Fernandes-Alnemri T, Wu J, Yu JW, Datta P, Miller B, Jankowski $W$ et al. The pyroptosome: a supramolecular assembly of ASC dimers mediating inflammatory cell death via caspase-1 activation. Cell Death Differ 2007; 14: 1590-1604.

80. Martinon F, Tschopp J. Inflammatory caspases and inflammasomes: master switches of inflammation. Cell Death Differ 2007; 14: 10-22.

81. Fink SL, Cookson BT. Pyroptosis and host cell death responses during Salmonella infection. Cell Microbiol 2007; 9: 2562-2570.

82. Labbe K, Saleh M. Cell death in the host response to infection. Cell Death Differ 2008; 15 : 1339-1349.

83. Willingham SB, Bergstralh DT, O'Connor W, Morrison AC, Taxman DJ, Duncan JA et al. Microbial pathogen-induced necrotic cell death mediated by the inflammasome components CIAS1/cryopyrin/NLRP3 and ASC. Cell Host Microbe 2007; 2: 147-159.

84. Martinon F, Gaide O, Petrilli V, Mayor A, Tschopp J. NALP inflammasomes: a central role in innate immunity. Semin Immunopathol 2007; 29: 213-229.

85. Ting JP, Willingham SB, Bergstralh DT. NLRs at the intersection of cell death and immunity. Nat Rev Immunol 2008; 8: 372-379.

86. Mormone E, Matarrese P, Tinari A, Cannella M, Maglione V, Farrace MG et al. Genotypedependent priming to self- and xeno-cannibalism in heterozygous and homozygous lymphoblasts from patients with Huntington's disease. J Neurochem 2006; 98: 1090-1099.

87. Overholtzer M, Mailleux AA, Mouneimne G, Normand G, Schnitt SJ, King RW et al. A nonapoptotic cell death process, entosis, that occurs by cell-in-cell invasion. Cell 2007; 131: $966-979$.

88. Le Bot N. Entosis: cell death by invasion. Nat Cell Biol 2007; 9: 1346

89. Doukoumetzidis K, Hengartner MO. Cell biology: dying to hold you. Nature 2008; 451: 530-531.

90. Schweichel JU, Merker HJ. The morphology of various types of cell death in prenatal tissues. Teratology 1973; 7: 253-266.

91. Martin DN, Baehrecke EH. Caspases function in autophagic programmed cell death in Drosophila. Development 2004; 131: 275-284. 